\title{
Ortopedi ve Travmatolojide pazarlama: dün, bugün, yarın
}

\author{
Marketing in orthopaedics and traumatology: yesterday, today, tomorrow
}

\author{
Hakan Onmuş ${ }^{1}$, Eren Dursun² \\ ${ }^{1}$ Plato Medikal Sistemler Sanayi Ltd. Şti., İstanbul \\ ${ }^{2}$ Renomed Co. Ltd., Ankara, Turkey
}

\begin{abstract}
Ortopedi ve Travmatoloji alanında medikal ürünlerin pazarlanması, diğer mal ve hizmetlerin pazarlanmasından farklılık gösterir. Geleneksel pazarlamada hedef, seçimi ve ödemeyi yapan ihtiyaç sahibi tüketicidir. Tıbbi malzemelerde ise ihtiyaç sahibi (hasta) seçimde ve ödemede esas olarak rol almaz. Dolayısıyla, hastanın korunması endüstri, ödeyici kurum ve hekimin ortak sorumluluğu haline gelir. Doktorların, malzeme seçiminde fiyat-yarar oranını değerlendirmeleri, malzemenin hasta yararına en iyisi olacağına karar vermeleri, yeni ürünlere hem güvenli hem de yeniliklerin önünü kapamayacak şekilde makul yaklaşmaları, etik kurallara uygun hareket etmeleri gereklidir. Endüstri yeni teknolojiler başta olmak üzere tüm ürünleri piyasaya sunarken hasta hakları ve karlılık arasındaki dengeyi çok iyi kurmalı ve bu yolda tüm hekim ilişkilerini etik kurallar dâhilinde tutmalıdır. İlgili devlet kurumlarının ise, fiyatların kalite, yararlılık ve dayanıklılık açısından doğru belirlenmesi ile başlayan ve endüstri hekim ilişkilerinin etik kurallara uygunluğunu kontrol etmeye kadar giden ciddi sorumlulukları vardır. Sonuç olarak, tıbbi pazarlama yapılırken temel amaç; hastanın hakları korunurken, katma değeri en yüksek ürüne ulaşmasını sağlamak ve bu süreçte kamu yararının korunmasını önde tutmak dolayısı ile bu yolda kanıtlanmamış yeni teknolojilerin ve kalitesiz ürünlerin piyasaya arzının önlenmesi olmalıdır. Günümüzde internet ve sosyal medya platformlarının gelişmesi ile birlikte pazarlama hekim odaklılıktan hasta odaklı tarafa kayma eğilimindedir. Bu yeni gelişmelere ayak uyduran taraflar avantaj sağlayacaktır.
\end{abstract}

Anahtar sözcülkler: ortopedik malzeme; pazarlama; tıbbi etik
Marketing in orthopedics and traumatology, in fact in all medical devices, is totally different from the marketing processes of other products and services. In conventional marketing, the target is the consumer who choses the product and as well pays for it. However, in medical devices market, the consumer (patient) has basically no role in the selection and payment process therefore industry, medical doctors and the state authorities take all together a responsible role for the protection of patient. Medical doctors should evaluate the price-benefit ratio in material selection, decide that the material will be the best for the benefit of the patient, approach the new products in a safe and reasonable way, and act in accordance with the ethical rules. Industry should establish the fine balance between patient rights and profitability, keep all physician relations within the ethical rules when introducing new technology products to the market. State institutions also have great responsibility starting with the definition of the price according to quality, durability and efficiency, bundled with controlling the relations of industry and healthcare professionals. As a result, the aim in medical device marketing should be to protect patient rights while providing the best proven, value added technology with reasonable prices as well as restraining the launch of unproven technologies and low quality products to the market. Today, with the development of internet and social media platforms, marketing of medical products tends to shift from physician-focused to patientoriented. Those who keep up with these new developments and changes within ethical values will benefit.

Key words: orthopedic device; marketing; medical ethics
P azarlama faaliyetleri pazarlamanın "4P"si denen bileşenlere ayrılır. Bu bileşenlerden Fiyat (Price), Promosyon ve Pazarlanan Yer (Place) ortopedik pazarlamada farklılık göstermektedir.

Geleneksel pazarlamada, müşteri hedeflenirken genelde malı satın alan da seçimi yapan da aynı kişidir.
Ortopedi ve Travmatoloji alanındaki ürünlerin pazarlanmasında ise hasta seçimde ve ödemede rol almaz. Hedef kitle hekim ve cerrahlardır. Aynı şekilde, geleneksel pazarlamada genellikle kullanıcı ürünün bedelini öder. Fiyat satıcı tarafından pazar koşullarına göre belirlenir. Ortopedi ve Travmatoloji alanında ürün

- İletişim adresi: Dr. Hakan Onmuş, Aykan Sokak 26/5 Emirgan, İstanbul Tel: 0533 -5158669 e-posta: honmus@platogrup.com

- Geliștarihi: 9 Ekim 2019 Kabul tarihi: 13 Kasım 2019 
pazarlamada ise fiyat geri ödeme kurumlarınca belirlenir. Dolayısı ile satıcı (firma) bu değişkeni kontrol edemez. Pazarlama aktiviteleri (promosyon) genellikle sağlık çalışanlarını hedeflemektedir. Kongreler, eğitim toplantıları, bilimsel çalışmalar ve satışa yardımcı olan tüm harcamalar pazarlama aktivitesi olarak kabul edilebilir.

Ortopedi ve Travmatoloji dalı, teknolojik ürünlerin ve tedavilerin yaygınlaşmasıyla beraber yüksek bütçeli bir disiplin haline dönüşmüştür. Dolayısı ile, pazarlama aktiviteleri de yüksek bütçelere sahiptir.

Yıllar içinde, endüstrinin sunduğu bu bütçenin kullanımını düzenleme ve denetleme gerekliliği ortaya çıkmıştır. Bu amaçla ülke ve bölge bazında kurulan yapılar, zaman içinde üye sayılarının artması ile güçlenmiş, koydukları kurallar ile piyasalara yön vermeye başlamışlardır.

Bu gelişmeye paralel olarak, devlet kurumları da benzer kuralların takipçisi olmuşlardır. Bu aktivitelerin temelinde hasta hakları, kamu yararının korunması ve tıbbi etik kuralların uygulanması vardır. Hasta haklarının korunması hekim, endüstri ve devlet kurumlarının sorumluluğu altındadır.

Yeni teknolojik implantların ilk kullanılmaya başlandığı dönemde, endüstrinin gelişme olarak sunduğu ürünler sağlık çalışanları tarafından hiçbir kısıtlama olmadan kullanılabiliyordu. Zaman içinde bu ürünlerin kullanımının devlet bütçelerinde yarattığı yükün artmasıyla birlikte, fiyatlar devlet tarafindan belirlenir olmuştur. Her yeni teknolojinin kolayca pazarlanıp hastalarda kullanılması nedeni ile oluşan olumsuz sonuçlar ve revizyon oranlarının artması, piyasaya arz konusunun ciddi kurumlar tarafından düzenlenmesi gerekliliği getirmiş, klinik öncesi testler ve uzun dönem sonuçlar ürünlerin pazarlamasında önem arz etmeye başlamıştır. Yeni teknolojik ürünlerin gelişmesi için endüstri, hekim işbirliği ve hastanın bilgilendirilerek bazı aşamalarda rol alması kaçınılmazdır. Bu konu da deneysel çalışmalarda etik kurulların kurulması ile çözümlenmiştir.

Günümüzde, Ortopedi ve Travmatoloji dalında ürün pazarlaması yanında sağlık kurumlarının ve hekimlerin tanıtım ve pazarlama aktivitelerinden de bahsetmek mümkündür. Yerel kanunların uygun olduğu bazı ülkelerde bu standart pazarlama aktivitesi olarak sürerken, kanunların izin vermediği ülkelerde, pazarlama ve tanıtım faaliyeti belli sınırlar dâhilinde sosyal medyada yürütülmektedir. Günümüzde hasta, internet sayesinde dünya üzerindeki tüm yeni teknolojiler hakkında bilgi edinebilmekte ve hekimden bunu talep edebilmektedir. Fertler hasta hakları konusunda daha bilgili ve bilinçli hale gelmişlerdir.

\section{DÜZENLEYICI KURALLAR}

Pazarlama aktiviteleri, satışı artırmak için kullanılan yöntemlerden birisidir. Ortopedi ve Travmatoloji alanında hedef kitle hekimler olduğu için, pazarlama faaliyetleri de kongreler, eğitim toplantıları, bilimsel çalışmalar olarak kendini göstermektedir. Bu yüzden Ortopedi ve Travmatoloji alanında pazarlama başlığını tıbbi etik kurallardan bağımsız düşünmek imkânsızdır. Bu kurallar, Hammurabi kurallarından (M.Ö. 1760) başlayarak, daha sonra Hipokrat'ın "Önce zarar verme (primum non nocere)" prensibi ile devam etmiş ve "American Academy of Physicians' First Code of Ethics (1847)" olarak vücut bulmuştur. ${ }^{[1]}$ Yirminci yüzyılın başlarında hasta onayı olmadan yapılan Nazi deneyleri sonrası, Nurenberg 1947 kurallarında hasta hakları öne çıkmıştır. Bu konuda basılı birçok yayın vardır. 2011'de revize edilen "AAOS Code of Ethics and Professionalism for Orthopaedic Surgeons" ile günümüze en uygun hale gelmiştir. ${ }^{[2]}$

Günümüzde, çok küçük değişiklikler ve eklemeler ile benzer kuralları uygulayan yerel ve bölgesel birçok endüstri bazlı kurum yardımı ile, endüstri ve hekim ilişkileri düzenlenmeye, hasta hakları öne çıkarılmaya ve etik bir kültür yaratılmaya çalışılmaktadır.

Hekim Birlikleri de benzer kurallar yayımlamışlardır. EFORT (Avrupa Ulusal Ortopedi ve Travmatoloji Birlikleri Federasyonu) 2013'te yayımladığı “Ethical Ortopedics for EFORT"[3] bildirgesinde bu kurallara ayrıntılı olarak değinmiş, hasta-hekim ve hekim-endüstri ilişkisini ayrıntılı olarak incelemiştir. Bu kurallar, hasta haklarını öne çıkartırken, hasta ve toplum ilişkilerinde tam şeffaflık ve dürüstlük gerekliliğini vurgulamaktadır. Hasta onayı alınırken, tedavinin riskleri yanında, eğer varsa endüstri ile iliş̧kileri ve herhangi bir çıkar çatışması durumu da şeffaf olarak paylaşılmalıdır.

Günümüz koşullarında, kısıtlı özel veya devlet kaynakları yararlılığı ispat edilmemiş pahalı tedaviler için kullanılmamalıdır. ${ }^{[4]}$ Eğer hekim bir deneysel çalışmaya katılmış ve bir ürün veya teknik geliştirmede rol almışsa, endüstri tarafından anlaşmalarla belirlenmiş ödemeler alması doğaldır. Ancak, sadece ismi kullanılarak pazarlama yapıldığı durumlarda, çalıştığı kurumun desteklenmesi daha doğrudur. Her durumda, hasta konu hakkında bilgilendirilmelidir. Ürünlerin satışlarını etkileyebilecek bilimsel sunumlarda tüm endüstri ilişkileri sunum öncesi ifşa edilmelidir. Devletler, profesyonel gruplar ve tıbbi yayıncı kuruluşlar çıkar çatışmalarını açıklama konusunda ikna edilmelidir. ${ }^{[5]}$

Endüstri-hekim ilişkileri şeffaf, dürüst ve açık olmalıdır. Bu ilişkiler belli kurallara bağlıdır. Hekimler 
bağımsız olmalıdır, endüstri ile yapılan cerrahi ve reçete yazma alışkanlıklarını içeren anlaşmalar kabul edilemez. Bu tip ilişkilerden hasta bilgilendirilmelidir. Endüstrinin ürün tanıtma toplantıları ve eğitimlere sponsorluk yapması doğaldır. Ancak, makul masrafların ödemelerinin hekim yerine kurumlarına yapılması gerekir.

Hekim ve kurumların kendilerini tanıtmak için yaptıkları tanıtım ve pazarlama aktivitelerinde, Amerikan Medikal Derneklerinin kuralları basitçe, hekimlerin toplumu yanlış bilgilendirmemesi gerektiğini söylemektedir: Günümüzün rekabet ortamında, ürün pazarlama yanında sağlık çalışanları ve kurumlar da kendi reklamlarını yapmaktadır. "Eğer bir hekim herhangi bir yöntemle (dergi, gazete sosyal medya) reklamını yaparsa, verilen bilgiler yanlış şekilde yönlendirici olmamalıdır". ${ }^{6]}$ Hekimler, günümüzde hastalar, diğer hekimler ve endüstri ile, konvansiyonel yöntemlerin yanı sıra sosyal medya üzerinden de ilişki kurabilmektedir. ${ }^{[7,8]} \mathrm{Bu}$ yöntemlerde de hasta gizliliğine önem verilmeli, yanlış yönlendirmelerden kaçınılmalı, bilgiler güncel tutulmalı ve bu iletişimin pozitif kadar negatif sonuçları olabileceği göz önünde bulundurulmalıdır. ${ }^{[9]}$

Hekimler gibi endüstri için de, iç işleyiş ve üçüncü taraf ilişkilerini düzenleyen kurallar, endüstri firmalarının üyesi olduğu gruplar tarafından uygulamaya koyulmuştur. Bu topluluklardan SAMED (Güney Afrika Medikal Cihazlar) yayımladığı "Code"[10] ile etik pazarlama ve iş pratikleri konusunda ayrıntılı bir yönlendirme sunar. Vizyonu, hastaların yenilikçi tıbbi cihazlara ulaşabildikleri sürdürülebilir bir endüstri yaratmaktır. Endüstri olarak hasta özelinde toplumsal sorumlulukları olduğunu kabul eder. Amaçlarını sağlık hizmeti sağlayıcıları ile uyum içinde verimli, efektif ve şeffaf sağlık hizmeti sunmak olarak tanımlar.

Ürün geliştirme, verimli, güvenli uygulama ve eğitim aşamalarında, endüstri ve sağlık çalışanı etkileşimi kaçınılmazdır. Tüm bu aşamalarda, üye firmalar sağlık çalışanlarının seçimlerine saygılı davranmak ve iş dürüstlüğünü korumak durumundadır. ${ }^{[10]}$ Advamed, Medtech ve benzer topluluklar, küçük farklılıklar ile aynı prensipleri üye firmalara uygulamaktadır.

Devletler de lokal kanun ve hükümler yanında bu kuruluşları desteklemektedir. Artık bu kuruluşlar birçok ülkede referans olarak alınmaya başlanmıştır. Devletler yenilikçi ve kanıtlanmış teknolojileri en uygun fiyata toplum adına satın almaya çalışırken, piyasa düzenleyici olarak kalitesiz ürün ve servislerin piyasaya arzını önlemelidir.

\section{PAZARLAMANIN GELECEĞi}

Günümüzde uygulanan ortopedik pazarlama yöntemleri zamanın gerisinde kalmıştır. 1900'lü yıllarda olduğu gibi, odaklanılan ürün özellikleridir. Bütçelerin büyük kısmı materyaller, paketleme, kongre standları, ürün numuneleri ve verimsiz internet sitelerine harcanmaktadır. Artık "Benim ürün özelliklerim seninkinden iyi” söylemi önemini kaybetmiştir.

Satış hâlâ bir ilişki satışıdır. Kârlılık hâlâ birçok sektörden yüksek olduğu için pazarlamada rekabet azdır.

Yarınlarda pazarlama tümüyle dijital olacaktır. Gerçek insanların sosyal medya ağlarına 24 saat bağlı olduğu günümüzde, hastalar ve hekimler internetten öğrenmekte, beraber çalışmakta ve paylaşmaktadırlar. Tıp, hasta odaklı ve hastalar tarafindan yönlendirilir olmaya başlamıştır. İnterneti bilinçli kullanan hastalar gereğinden fazla bilgiye sahiptir. Doktora körü körüne teslim olan hasta profili giderek azalmaktadır. Hasta ve hasta yakınları günümüzde klinik çalışmalara, implant performans sonuçlarına, cerrahi tekniklere ve hastane performanslarına kolayca ulaşabilmektedir.

Firmalar, hastalarca kolayca anlaşılabilir bir yarar sunuyorlarsa, hekim yerine hastaya ulaşmalıdır. İnternette sunulan içerik önemlidir. Eğer içerik değerli ve ilgi çekici ise işe yarar. Bunun için tüm platformları kullanmak gerekir. Dijital pazarlama ile yapılabilecekler geleneksel yöntemle imkânsızdır. Örneğin, belli bir hasta profiline yönelik içerik hazırlamak ve ulaştırmak çok kolaydır. Gelenekselin aksine, firma her hafta kampanya değiştirebilir ve bu pazarlama aktivitesi her durumda şu andakinden daha az maliyetli olacaktır. Dijital pazarlama klinik çalışmalarda güçlü bir kaldıraç olmuştur. ileride denek seçimleri \%100 internet üzerinden yapılacaktır. Böylece, kabul ret kriterleri hassasiyetle takip edilebilecek, daha ucuza mal edilecek ve çalışmayı genişletmek istenirse kolayca yapılabilecektir.

Yakın gelecekte klinik veri geçer akçe olacak, nesnelerin interneti ve giyilebilir cihazlar ile hem hasta hem de firmalar veri toplayacak ve bu verileri satarak veya pazarlayarak avantaj edineceklerdir.

\section{SONUÇ}

Endüstri, yeni teknoloji ürünleri piyasaya sunarken hasta hakları ve kârlıık arasındaki dengeyi çok iyi kurmalı ve bu yolda tüm hekim ilişkilerini farklı bölgesel kurumlarca belirlenmiş ve kabul edilmiş kurallara uygun sınırlarda tutmalıdır. 
Ödeyici olarak ilgili devlet kurumlarının ise, fiyatların kalite, yararlıık ve dayanıklılık açısından doğru belirlenmesi ile başlayan ve endüstri-hekim ilişkilerinin etik kurallara uygunluğunu kontrol etmeye kadar giden ciddi sorumlulukları vardır.

Endüstri günümüzde, Ortopedi ve Travmatoloji alanındaki pazarlamada cerrahları ve meslek derneklerini hedeflemektedir. Bu yüzden, bu konuda şeffaflık ve hasta haklarının öne çıkartılması daha da önem kazanmaktadır. Bu yolda endüstri ve meslek dernekleri kurallar belirlemişler, devletler de kanun ve yönetmelikler hazırlamışlardır. Bu ayrıntılı kurallar yanında, tüm fertlerin vicdanları işleyişte en önemli faktör olmaya devam etmektedir.

İnternet ve sosyal medyanın yaygınlaşması ile birlikte, pazarlama günümüzde hekim odaklı olmaktan çıkıp hasta odaklı hale gelmeye başlamıştır. Hastalar, her türlü bilgiye internet üzerinden kolayca ulaşıp talep edebilmekte ve daha belirleyici olabilmektedir.

Hekimler ve kurumlar da aynı yöntemle hastalara kolayca ulaşabilmekte, kendi çalışmalarını tanıtabilmekte ve iyi sonuçları paylaşabilmektedir. Yakın gelecekte, daha az maliyetli dijital pazarlama giderek daha önemli hale gelecektir. Bu gelişmeye ayak uydurabilen paydaşların öne çıkması kaçınılmazdır.

\section{KAYNAKLAR}

1. American Academy of Physicians. Code of ethics. American Medical Association, Chicago; 1847. Erişim: http://ethics. iit.edu/ecodes/sites/default/files/Americaan\%20Medical\%20 Association\%20Code\%20 of\%2 Medical\%20 Ethics\%20 \%281847\%29.pdf

2. American Academy of Orthopedic Surgeons \& the American Association of Orthopedic Surgeons. Code of ethics and professionalism for orthopedic surgeons (Adopted: October 1988. Revised: 1991, 1995, 2001, 2002, 2004, 2005, 2009, 2011)

3. Ethical Orthopedics for EFORT; 2013. Erişim: https:// www.efort.org/wp-content/uploads/2014/09/Ethical_ orthopaedics_2014report.pdf

4. Lie RK. Research ethics and evidence based medicine. J Med Ethics 2004;30(2):122-125. Crossref

5. Okike K, Kocher MS, Wei EX, Mehlman CT, Bhandari M. Accuracy of conflict-of-interest disclosures reported by physicians. N Engl J Med 2009;361(15):1466-74. Crossref

6. Havard JD. Advertising by doctors and the public interest. BMJ 1989;298(6678):903-4. Crossref

7. Estroff SE, Walker RL. Confidentiality: concealing "things shameful to be spoken about". Virtual Mentor 2012;14(9):7337. Crossref

8. American Academy of Orthopedic Surgeons \& the American Association of Orthopedic Surgeons. Social media in healthcare -a primer for orthopaedic surgeons; 2012.

9. Timimi FK. Medicine, morality and health care social media. BMC Med 2012;10:83. Crossref

10. Medical Device Code of Ethical Marketing and Business Practice "The Code" Version 3 (SAMED); 2017. Erişim: http:// www.samed.org.za/Filemanager/userfiles/Medical\%20 Device\%20Code\%20of\%20Ethical\%20Marketing\%20and\%20 Business\%20Practice\%20July\%202017.pdf 